\title{
A Comparative Study of Mechanical Properties, Thermal Conductivity, Residual Stresses, and Wear Resistance of Aluminum-Alumina Composites Obtained by Squeeze Casting and Powder Metallurgy
}

\author{
JUSTYNA MAJ, WITOLD WEGGLEWSKI, KAMIL BOCHENEK, LUKASZ ROGAL, \\ STEFANIA WOŹNIACKA, and MICHAŁ BASISTA
}

\begin{abstract}
Squeeze casting and powder metallurgy techniques were employed to fabricate $\mathrm{AlSi} 12 / \mathrm{Al}_{2} \mathrm{O}_{3}$ composites, which are lightweight structural materials with potential applications in the automotive industry. The impact of the processing route on the material properties was studied. Comparative analyses were conducted for the Vickers hardness, flexural strength, fracture toughness, thermal conductivity, thermal residual stresses, and frictional wear. Our results show that the squeeze cast composite exhibits superior properties to those obtained using powder metallurgy.
\end{abstract}

https://doi.org/10.1007/s11661-021-06401-7

(C) The Author(s) 2021, corrected publication 2021

\begin{abstract}
AluminUM matrix composites (AMCs) are one of the most intensively studied metal-ceramic material systems because of their excellent mechanical and thermal properties, high durability, low density, and relatively low raw material cost. These superior properties have resulted in the widespread industrial use of AMCs, especially in the automotive and aerospace sectors. There are two main categories of AMCs processing techniques: (i) liquid-phase processes such as stir casting,${ }^{[1-3]}$ squeeze casting, ${ }^{[4-6]}$ gas pressure-assisted infiltration, ${ }^{[7,8]}$ pressureless infiltration, ${ }^{[9,10]}$ and (ii) solid-state processes with powder metallurgy being of primary importance. ${ }^{[1]}$ Liquid-phase techniques are considered more suitable for the mass production of AMCs owing to their low cost and ease of upscaling. ${ }^{[3]}$ A comprehensive overview of the fabrication, microstructure, properties, and applications of AMCs can be found in the literature. ${ }^{[12]}$

The microstructure of interpenetrating phase composites obtained by the infiltration of molten aluminum alloys into porous ceramic preforms via squeeze casting
\end{abstract}

JUSTYNA MAJ, WITOLD WEGLEWSKI, KAMIL BOCHENEK, STEFANIA WOŹNIACKA, and MICHAŁ BASISTA are with the Institute of Fundamental Technological Research, Polish Academy of Sciences, Pawińskiego 5B, 02-106 Warsaw, Poland. Contact e-mail: mbasista@ippt.pan.pl. ŁUKASZ ROGAL is with the Institute of Metallurgy and Materials Science, Polish Academy of Sciences, 30-059 Kraków, Poland.

Manuscript submitted January 6, 2021; accepted July 12, 2021

Article published online August 12, 2021
(SC) differs from that obtained by hot pressing (HP) of aluminum/ceramic powder mixtures. ${ }^{[13]}$ In the squeeze cast composites, both the ceramic reinforcement and the aluminum matrix form continuous interpenetrating networks. However, in hot-pressed composites, the ceramic reinforcements are in the form of discrete objects such as particles, fibers, and whiskers embedded in a continuous metal matrix.

This study seeks to answer the question of whether the AMCs produced by (i) $\mathrm{SC}$ and (ii) $\mathrm{HP}$ exhibit significant differences in their mechanical and thermal properties, as well as their processing-induced residual stresses and wear resistance. The study material is a composite made of 54 vol pet AlSi12 alloy and 46 vol pet $\mathrm{Al}_{2} \mathrm{O}_{3}$ (abbreviated as $\mathrm{AlSi} 12 / \mathrm{Al}_{2} \mathrm{O}_{3}$ ). This material was selected owing to its potential application in brake disks for the automotive industry. Table I shows the chemical composition of the AlSil2 alloy (also known as EN AC-44200). Comparative analysis of the flexural strength, fracture toughness, Vickers hardness, thermal conductivity, residual thermal stresses, and frictional wear of the AlSi12 $/ \mathrm{Al}_{2} \mathrm{O}_{3}$ composites fabricated by $\mathrm{SC}$ and $\mathrm{HP}$ is provided.

In the fabrication of $\mathrm{AlSi} 12 / \mathrm{Al}_{2} \mathrm{O}_{3}$ composite by $\mathrm{SC}$, the first step is the preparation of porous ceramic preforms by using the tape casting technique. For this purpose, HVA FG alumina powder (Almatis; 99.97 pct purity, average particle size $4.8 \mu \mathrm{m}$ ) was used. Porous alumina preforms were obtained by adding a pore-forming agent (rice starch) to the ceramic slurry, followed by burning out the organic materials to leave holes. Finally, 
Table I. Chemical Composition of AISi12 Alloy (EN AC-44200)

\begin{tabular}{lcccrrrr}
\hline Chemical Composition (Weight Percent) & $\mathrm{Si}$ & $\mathrm{Fe}$ & $\mathrm{Cu}$ & $\mathrm{Mn}$ & $\mathrm{Al}$ \\
\hline & 10.5 to 13.5 & 0.55 & 0.05 & 0.35 & rest \\
\hline
\end{tabular}

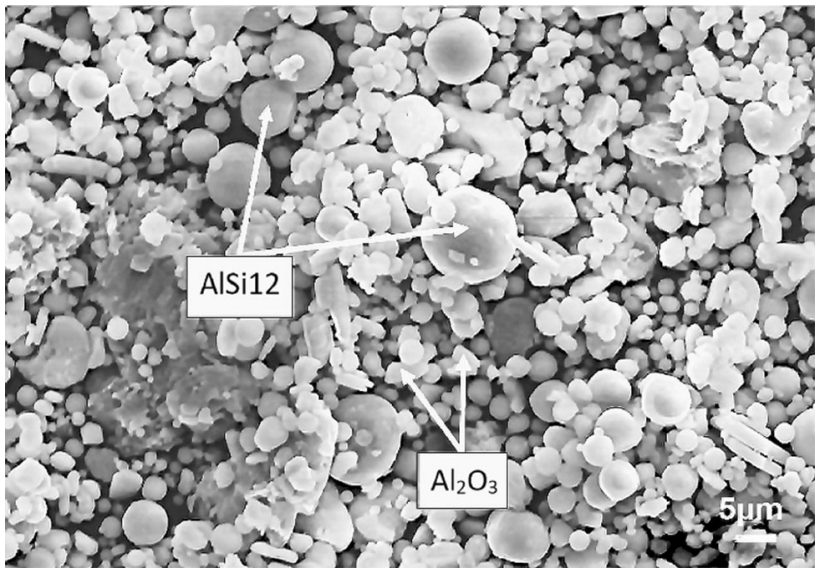

Fig. 1-SEM micrograph of $\mathrm{AlSi} 12+46$ vol pet $\mathrm{Al}_{2} \mathrm{O}_{3}$ powder mixture after $5 \mathrm{~h}$ of milling.

the material was sintered at $1660^{\circ} \mathrm{C}$. The open porosity (54 pct) and pore size distribution of the preforms were evaluated using mercury porosimetry (Poremaster 60, Quantachrome). Then, the porous alumina preforms were preheated to approximately $700{ }^{\circ} \mathrm{C}$ and infiltrated with a molten AlSi12 alloy (NewMet; purity 99 pct) by SC under a pressure of $100 \mathrm{MPa}$. The pore network and applied pressure enabled good quality infiltration. Further details on the preform preparation and AlSi12 alloy infiltration are provided in our previous paper. ${ }^{[14]}$

In parallel, the $\mathrm{AlSi} 12 / \mathrm{Al}_{2} \mathrm{O}_{3}$ composite was fabricated using a powder metallurgy method. The powder mixture was prepared in a planetary ball mill (Fritsch Pulverisette 5) in hexane solution at a speed of $100 \mathrm{rpm}$, with a ball-to-powder weight ratio of BPR 5:1, and a total milling time of 5 hours. An SEM micrograph of the AlSi12/ $\mathrm{Al}_{2} \mathrm{O}_{3}$ powder mixture is shown in Figure 1.

The powder mixture was consolidated by hot pressing (HP) in a vacuum furnace (HP20-4560 FP34 Thermal Technology) at $630{ }^{\circ} \mathrm{C}$ using a heating rate of $10{ }^{\circ} \mathrm{C} /$ min, pressure of $60 \mathrm{MPa}$, and dwell time of 3 hours. The cooling from 630 to $500{ }^{\circ} \mathrm{C}$ proceeded at $10{ }^{\circ} \mathrm{C} / \mathrm{min}$ and was followed by free cooling from $500{ }^{\circ} \mathrm{C}$ to room temperature.

The relative density measured by the Archimedes' method was 94.16 pct for the hot-pressed $\mathrm{AlSi} 12 / \mathrm{Al}_{2} \mathrm{O}_{3}$ sample and 96.67 pct for the squeeze cast sample. The microstructures of the two materials are similar (Figures 2(a) and (b). However, the SC material with an interpenetrating structure exhibits slightly more regular shapes on the polished surface (Figure 2(a)). By contrast, the hot-pressed material (HP), which has a matrix-inclusion type of microstructure, shows sharper grain boundaries and broader size distribution of the ceramic reinforcement (Figure 2(b)). Detailed geometrical characteristics (e.g., EqDiameter, perimeter, length, width, and circularity) were acquired using a Nikon Eclipse MA200 optical microscope with the NIS-Elements software for image analysis, and are provided in Table II.

In both materials, the amount of interfaces between the alumina reinforcement and the AlSi12 matrix is large. The bonding between the matrix and the reinforcement, which is correlated with the processing method, could also affect the studied properties.

The results of all the experiments performed on the SC and HP composites are collectively shown in Table II. The processing-induced thermal residual stresses (TRS), which are unavoidable in either of the two fabrication techniques due to the disparity in the thermal expansion coefficients of the phase materials, can be detrimental to the integrity of the material. ${ }^{[15]}$ Therefore, the comparative analyses also included TRS measurements by neutron diffraction.

The Vickers hardness was measured using a DuraScan-20 apparatus equipped with a standard pyramidal indenter. A load of $10 \mathrm{~kg}$ was applied, and at least five indentations were made to obtain the average hardness value. In addition, the Vickers hardness was evaluated at a load of $2 \mathrm{~kg}$ using a VH1102 Buehler microindenter. The results of both tests (Table II) revealed significantly lower hardness of the HP composite than that of the SC composite. This can be attributed to weaker bonding of $\mathrm{Al}_{2} \mathrm{O}_{3}$ grains to the AlSi12 matrix in the HP material due to the incomplete sintering of the composite and its higher porosity.

To obtain a deeper insight into the bonding between the $\mathrm{Al}_{2} \mathrm{O}_{3}$ grains and AlSi12 alloy, TEM experiments were performed on the SC and HP samples. The structural studies were performed in bright-field transmission electron microscopy (BF-TEM) mode using Tecnai G2 F20, FEI microscope. Thin foils for the studies were cut out using FEI Quanta 200 dual-beam focused ion $(\mathrm{Ga}+)$ beam machine equipped with Omniprobe $^{\mathrm{TM}}$ lift-out system. The TEM results show oxide layers and nanometric cracks at the interfaces between the aluminum alloy and the aluminum oxide in the HP material (Figures 3(a) and (b)) as well as a nonsmooth (wavy) interface shape (Figure 3(c)). These microstructural flaws can impair the bond strength and, consequently, the hardness of the material. By contrast, the interfaces in the SC material (Figure 3(d)) are of a better quality, which is reflected in its superior hardness compared with the HP material (Table II).

Thermal conductivity $\lambda(T)$ was evaluated by the laser flash method (Laser Flash Analyzer LFA457/Netzsch) in the temperature range of 50 to $300{ }^{\circ} \mathrm{C}$. For both materials, $\lambda(T)$ decreased with increasing temperature: by 20 pct for $\mathrm{AlSi} 12 / \mathrm{Al}_{2} \mathrm{O}_{3}(\mathrm{SC})$ and $30 \mathrm{pct}$ for $\mathrm{AlSi} 12 / \mathrm{Al}_{2} \mathrm{O}_{3}(\mathrm{HP})$. This is at variance with the results of Scherm et al. ${ }^{[16]}$ obtained for an aluminum-alumina composite with similar volume 


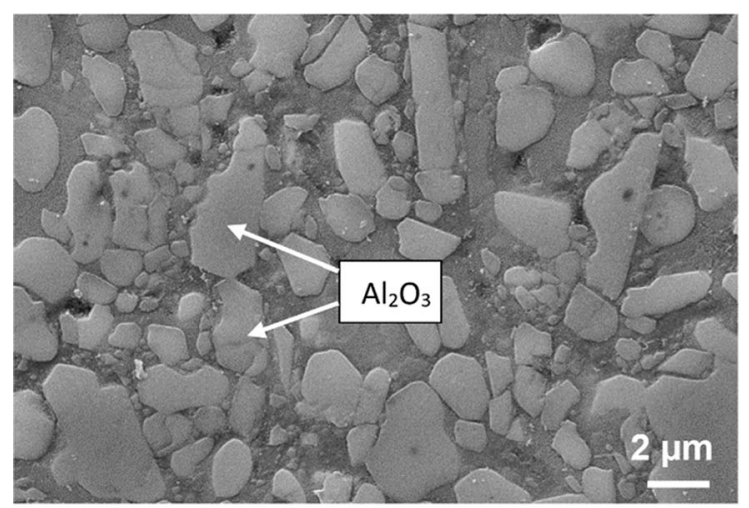

(a)

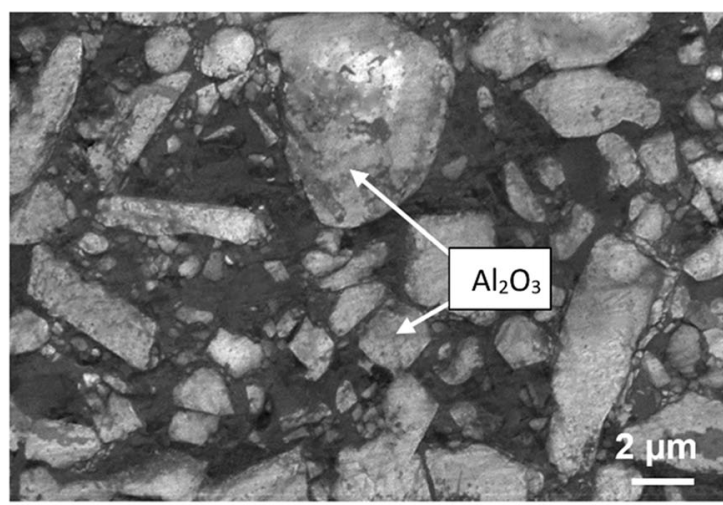

(b)

Fig. 2-SEM images of $\mathrm{AlSi} 12 / \mathrm{Al}_{2} \mathrm{O}_{3}$ samples: (a) infiltrated via squeeze casting (SC); (b) sintered by hot pressing (HP).

fractions, where $\lambda(T)$ was nearly insensitive to temperature in the range of $\left(50\right.$ to $\left.300{ }^{\circ} \mathrm{C}\right)$. However, a recent study ${ }^{[17]}$ reported a 20 pet drop in $\lambda(T)$ for an $\mathrm{Al} / 30 \mathrm{SiC}$ composite fabricated by powder metallurgy (Spark Plasma Sintering, SPS) upon a temperature rise from 50 to $300{ }^{\circ} \mathrm{C}$. A reduction in thermal conductivity exceeding 50 pct was also observed for aluminum-alumina coatings. ${ }^{[18]}$ In our study, the interpenetrating structure of the SC material somewhat improved the conductivity compared to that of the hot-pressed (HP) material, but the differences were relatively small (see Table II). The major cause for the similar $\lambda(T)$ behavior in both materials seems to be their identical chemical composition rather than the microstructure's fine details.

The fracture toughness (SEVNB probe) and flexural strength were determined by four-point bending using a Zwick/Roell ProLine Z050 universal testing machine. Prismatic notched and unnotched specimens $\left(25 \times 2 \times 3 \mathrm{~mm}^{3}\right)$ were prepared according to ISO 23146:2012 standard. ${ }^{[19]}$ They were loaded to fracture at a cross-head speed of $0.5 \mathrm{~mm} / \mathrm{min}$, and the peak force was registered. The notch depths were measured using an optical microscope, and the three measurements were averaged.

The fracture toughness and flexural strength of the SC and HP composites are listed in Table II. Although their microstructures were of different types (interpenetrating metal-ceramic networks vs. metal matrix with dispersed ceramic inclusions), the $K_{\mathrm{IC}}$ values were almost equal. Local stress concentrators, such as sharp corners and edges in the ceramic reinforcement, which were present in both composites (see Figures 2(a) and (b)) had a more significant impact on the fracture toughness ${ }^{[20]}$ than the fact that the ceramic reinforcement was continuous in the SC composite and discontinuous in the HP composite. In addition to the open porosity produced by burning out the pore-forming organics, some very fine voids were formed in the alumina preform of the SC composite resulting from particle-to-particle contact. These voids remain uninfiltrated even at very high pressures. ${ }^{[21]}$ Moreover, since the uninfiltrated voids are irregularly shaped, they could further reduce the fracture toughness value of the SC composite making it comparable to that of the HP material (Table II).
According to the data in Table II, the flexural strength of the SC material is more than 100 pct higher than its HP counterpart. This could be because of the continuity of the ceramic preform, which transfers the load effectively from the softer AlSi12 matrix to the stiffer alumina preform. ${ }^{[22]}$ Another reason for the inferior flexural strength of the HP material are the interfacial defects revealed by the TEM analysis (Figures 3(a) through (c)).

SEM images of the fracture surfaces were analyzed to better understand the deformation and fracture mechanisms (Figure 4). The SC material revealed a larger share of elastic-plastic fracture compared to the HP analog. Before the failure, plastic deformation and necking of the aluminum alloy ligaments occurred. The flat surfaces of alumina visible in Figure 4(a) indicate that the ceramic grains in the SC material were fractured rather than pulled out, which can be interpreted as the interfaces being stronger than the reinforcing phase. ${ }^{[23]}$ The micrograph in Figure 4(a) shows a more developed surface with only a trace of brittle fracture compared to the composite in Figure 4(b). This leads to a notable difference between the flexural strengths of the two materials. The porosity formed during manufacturing, that is, 5.84 pet in the HP material and 3.33 pet in the SC material, contributed to the lower flexural strength of the AlSi12/ $\mathrm{Al}_{2} \mathrm{O}_{3}(\mathrm{HP})$ composite.

A closer examination of the fracture surface of the HP material in Figure 4(b) reveals debonding sites at the AlSi12/ $/ \mathrm{Al}_{2} \mathrm{O}_{3}$ interface. Such defects are less evident in the SC material (Figure 4(a)). These interfacial microcracks, which can be interpreted as weak bonding between the two phases after hot pressing, reduced the hardness of the HP material (see Table II).

Thermal residual stresses (TRS) were evaluated by the neutron diffraction (ND) method. The experiments were performed using a neutron strain scanner instrument E3 at Helmholtz-Zentrum Berlin (Germany). ${ }^{[24]}$ Measurements were performed at five points, in the middle of each sample's thickness, in three orthogonal directions: one normal $(z)$ and two in-plane ( $x$ and $y$ ) to obtain the average residual stress in the AlSi12 matrix and the alumina reinforcement. ND experiments were also 


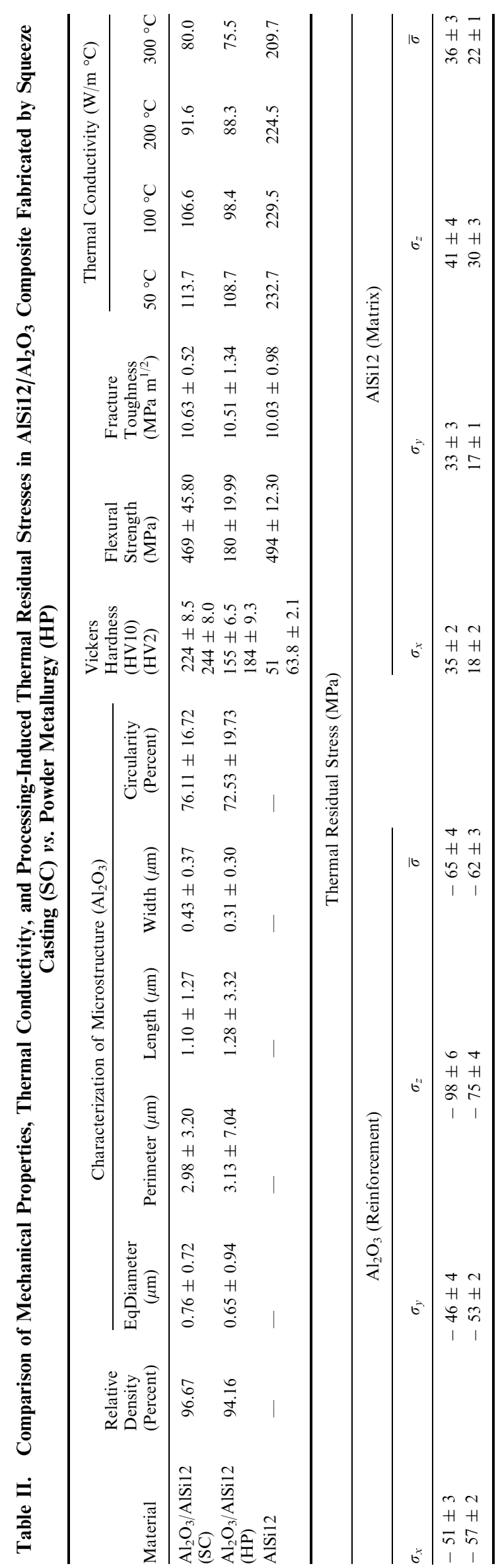




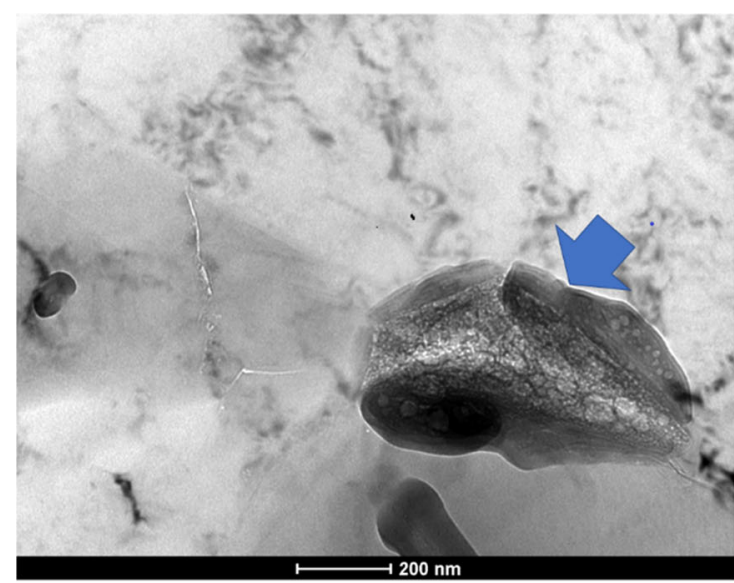

(a)

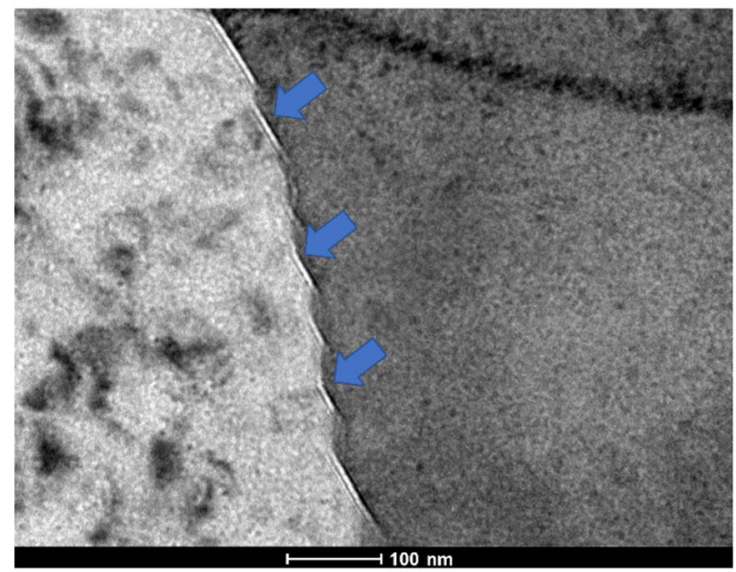

(c)

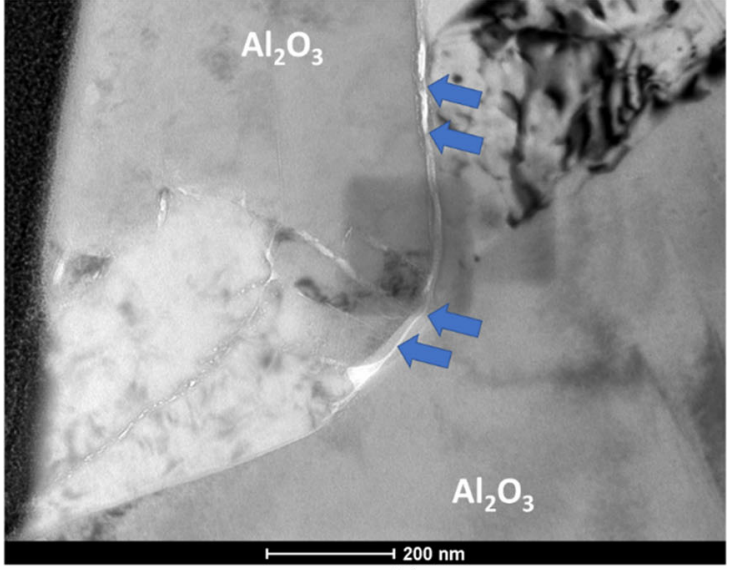

(b)

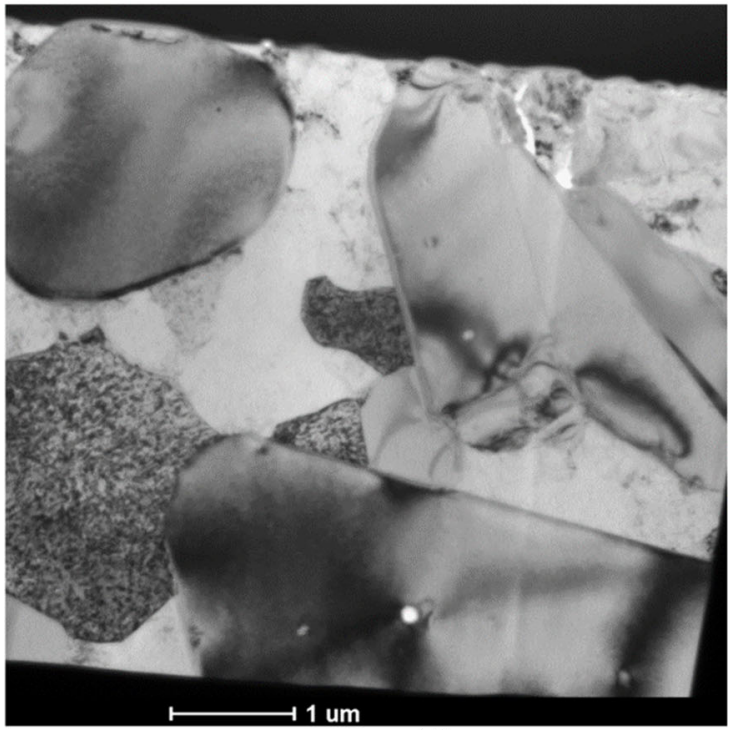

(d)

Fig. 3-TEM images showing interfaces in AlSi12/ $\mathrm{Al}_{2} \mathrm{O}_{3}$ samples: (a) through $(c)$ hot-pressed (HP); (d) squeeze cast (SC). Oxides (a), nanometric cracks (b), and wavy interfaces (c) are visible in the HP sample as indicated by arrows. In the SC sample (d) interfaces show fewer structural flaws, hence a better bonding strength could be achieved.

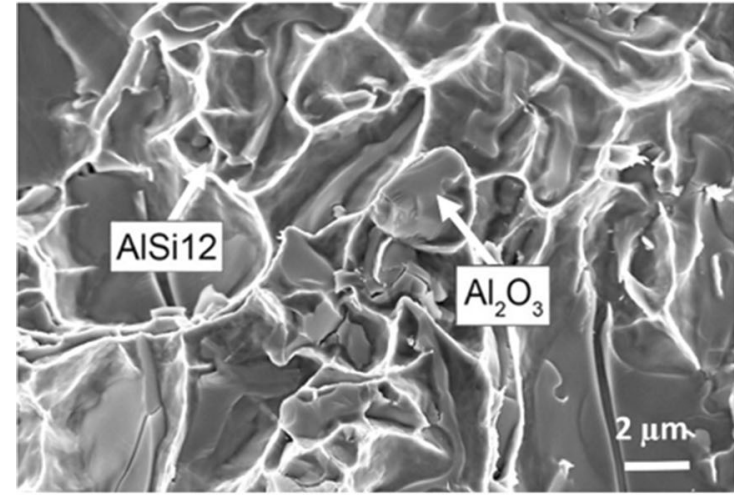

(a)

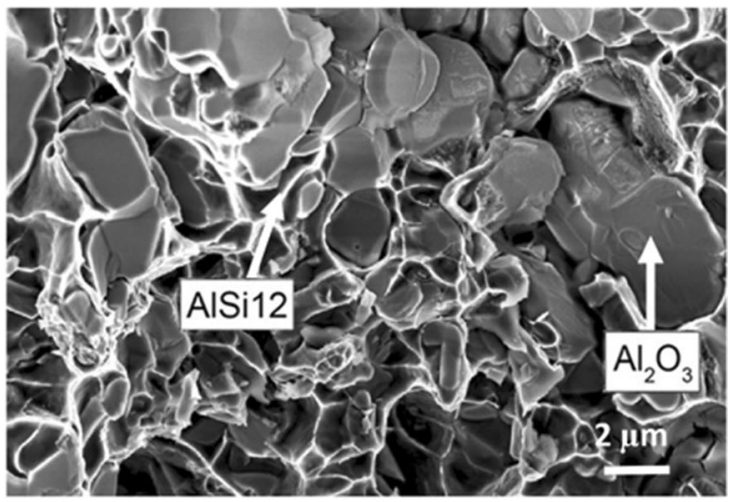

(b)

Fig. 4 - SEM micrographs of the fracture surfaces of (a) squeeze cast (SC), and (b) sintered (HP) $\mathrm{AlSi} 12 / \mathrm{Al}_{2} \mathrm{O}_{3}$ composites. 


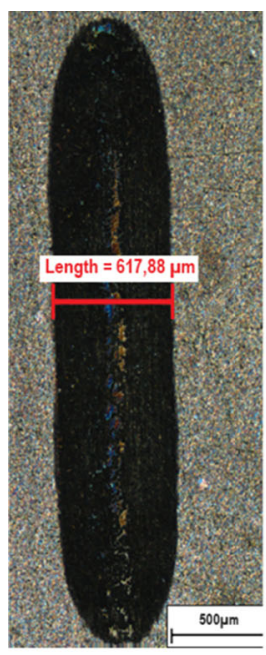

(a)

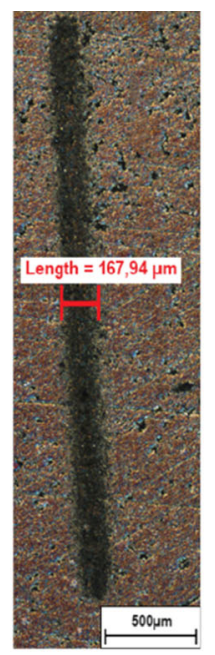

(b)

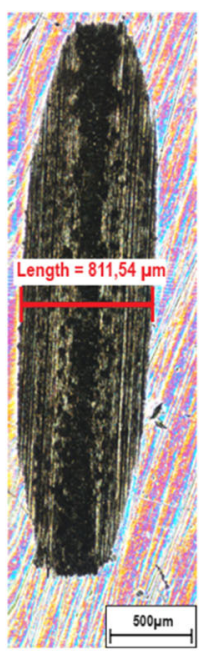

(c)

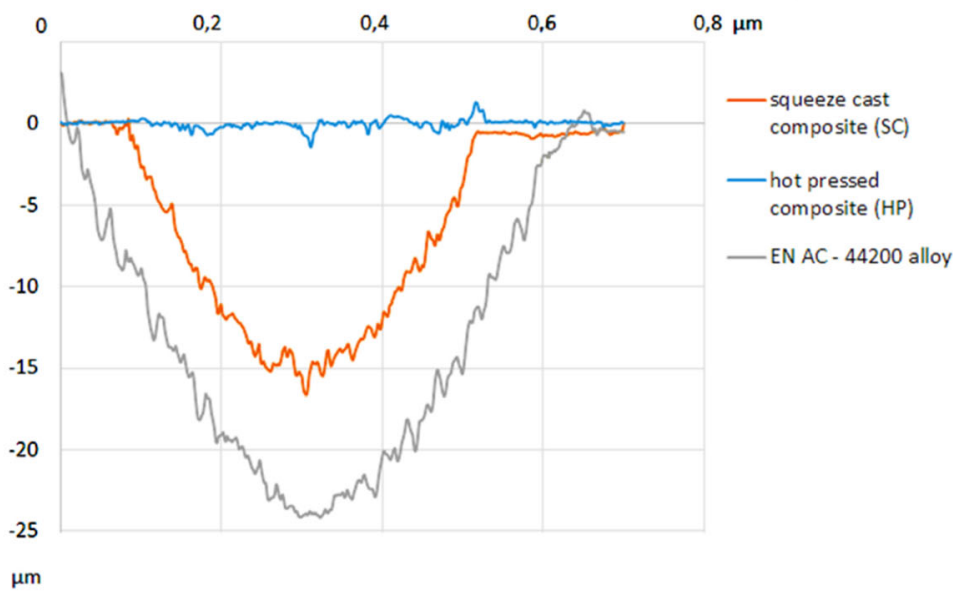

(d)

Fig. 5-Wear tracks on sample surface after ball-on-flat test: (a) squeeze cast $\mathrm{AlSi} 12 / \mathrm{Al}_{2} \mathrm{O}_{3}(\mathrm{SC}),(b)$ hot-pressed $\mathrm{AlSi12} / \mathrm{Al} \mathrm{O}_{3}(\mathrm{HP}),(c)$ EN AC-44200 unreinforced alloy; $(d)$ profiles of wear track cross-sections of tested materials. Normal load was $0.25 \mathrm{~N}$.

conducted for pure $\mathrm{Al}_{2} \mathrm{O}_{3}$ and $\mathrm{AlSi} 12$ powders to fix a reference state for the TRS calculations. A gauge volume of $2 \times 2 \times 2 \mathrm{~mm}^{3}$ was used to sample sufficient grains for a statistical average while ensuring adequate TRS distribution resolution. The neutron wavelength was $\lambda=1.47 \AA$. The scattering angle, $2 \theta$, was used to calculate the lattice spacing, $d$, from Bragg's law, $\lambda=2 d \sin \theta$. The elastic strains due to TRS were calculated according to $\varepsilon_{i}=\left(d_{i}-d_{0}\right) / d_{0}=\left(q_{0} / q_{i}\right)-1$, where $I=x, y, \mathrm{z}, d_{0}$ is the interplanar distance between the lattice planes from the ND measurements on pure $\mathrm{Al}_{2} \mathrm{O}_{3}$ and $\mathrm{AlSi}$ powders (reference state), $q_{0}$ is the corresponding Bragg peak position in the reciprocal space obtained from the powder measurements, $d_{i}$ is the measured interplanar distance, and $q_{i}$ is the corresponding Bragg peak position in the $x, y$, and $z$ directions. The strain was averaged over all peaks in one direction. Once the strains were known, the corresponding residual stresses were obtained using Hooke's law. Young's modulus and Poisson's ratio were $380 \mathrm{GPa}$ and 0.22 , respectively, for the sintered alumina, and $70 \mathrm{GPa}$ and 0.34 for the AlSi12 alloy. ${ }^{[14]}$ The TRS components shown in Table II are compressive in the ceramic phase and tensile in the AlSi12 matrix. The average TRS values $(\bar{\sigma})$ are comparable in both materials, with a slightly lower value for HP because of its higher porosity, which can partially accommodate the residual stresses. ${ }^{[25,26]}$

The composites and base aluminum alloy were tested for frictional wear resistance using reciprocating sliding tests under dry conditions: (i) ball-on-flat and (ii) pin-on-flat. The latter was performed because of a larger contact surface, which is essential for the targeted application of $\mathrm{AlSi} 12 / \mathrm{Al}_{2} \mathrm{O}_{3}$ as a brake disk material. Before the tests, the surfaces were polished with 320 , 600 , and 1200 grit $\mathrm{SiC}$ papers. The ball-on-flat test was conducted using a customized wear tester ${ }^{[27]}$ with a 6-mm-diameter sapphire ball, load of $0.25 \mathrm{~N}$, stroke length of $3 \mathrm{~mm}$, rate of 268 cycles/min, and duration of 1.5 hours.

The pin-on-flat wear test was performed using a Taber Linear Abraser model 5750 under a normal load of $19.61^{\circ} \mathrm{N}$, stroke length of $13 \mathrm{~mm}$, and rate of 60 cycles/ min, with a total of 1200 cycles of back-and-forth stroke arm movements. The abrasive ceramic pin (H-10 Calibrade, Taber Industries) was a flat-ended cylinder with a diameter of $6.35 \mathrm{~mm}$. Before each test, the tip was polished with 180 grit $\mathrm{SiC}$ paper. The scanning profilometry method (T8000 Nanoscan, Hommel Etamic) was employed to analyze the surfaces. The wear track widths were evaluated using a Nikon Eclipse MA200 optical microscope. In the pin-on-flat test, the applied pressure was equal $0.62 \mathrm{MPa}$ and was constant during the test because of the flat-ended pin. This is approximately half the nominal pressure exerted on brake pads in regular cars. ${ }^{[28]}$ The stroke length and speed were determined based on the sample dimensions and parameters of the Taber Linear Abraser 5750.

In the ball-on-flat test (Figure 5), the highest wear resistance was observed in the HP composite (Figures 5(b) and (d)). The SC composite exhibited a wider wear track and a deeper wear profile. Here, considerable microcracking of the ceramic skeleton was observed, resulting in an increased material loss rate. Both composites exhibited higher wear resistance than the bare AlSi12 matrix.

In the pin-on-flat test (Figure 6), where the contact surface between the flat pin and the specimen was much larger, both the SC and HP composites showed superior wear resistance compared to the AlSi12 matrix (Figure 6(d)). According to Prasad et al., ${ }^{[29]}$ such behavior can be associated with the suppressed tendency of microcracking in the ceramic phase due to increased frictional heat. Notably, SC performed better than HP (Figure 6(d)). 

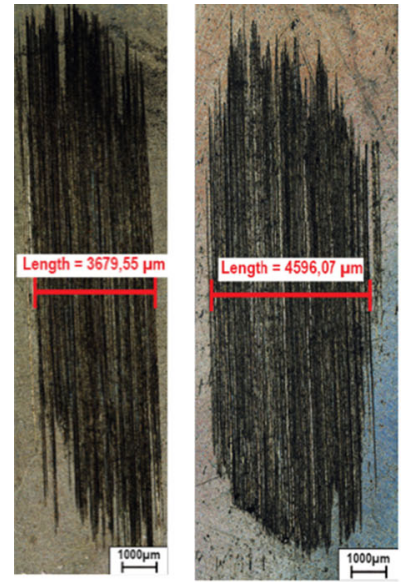

(a)

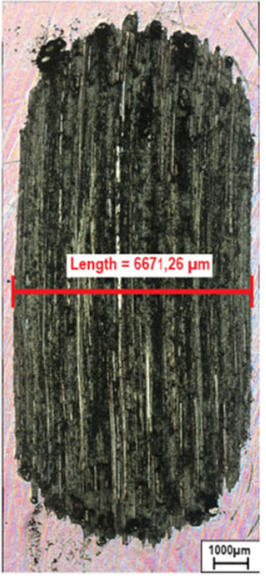

(c)

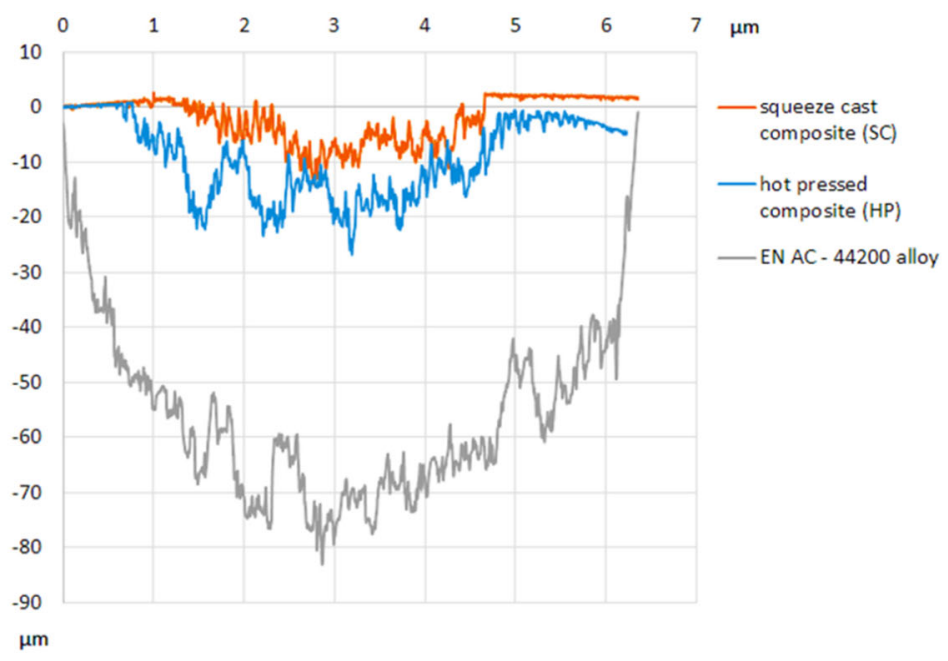

(d)

Fig. 6-Wear tracks on sample surface after pin-on-flat test in Taber apparatus: (a) squeeze cast $\mathrm{AlSi}_{12} / \mathrm{Al}_{2} \mathrm{O}_{3}(\mathrm{SC}),(b)$ hot-pressed $\mathrm{AlSi} 12 /$ $\mathrm{Al}_{2} \mathrm{O}_{3}$ (HP), (c) EN AC-44200 unreinforced alloy; (d) profiles of wear track cross-sections. Normal load was $19.61 \mathrm{~N}$.

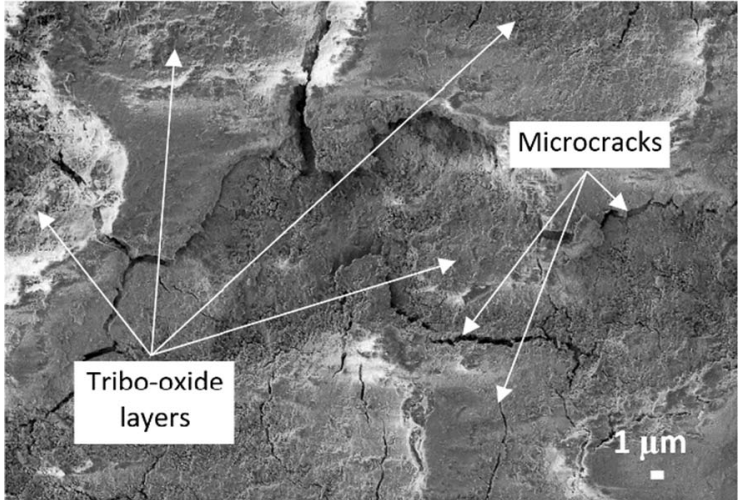

(a)

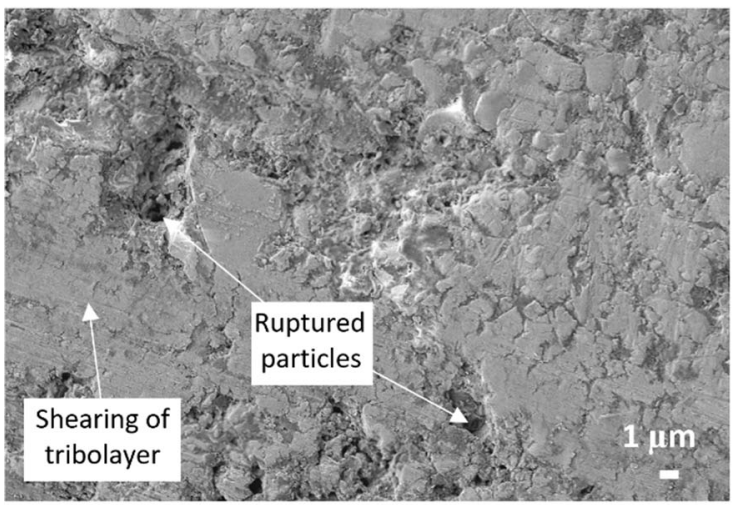

(c)

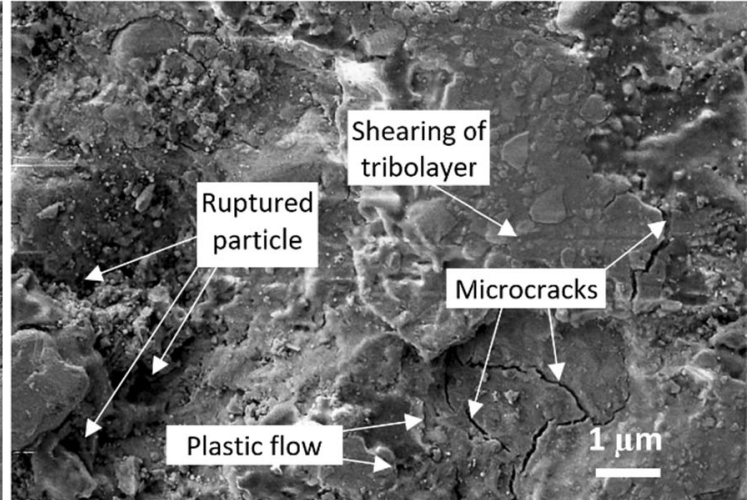

(b)

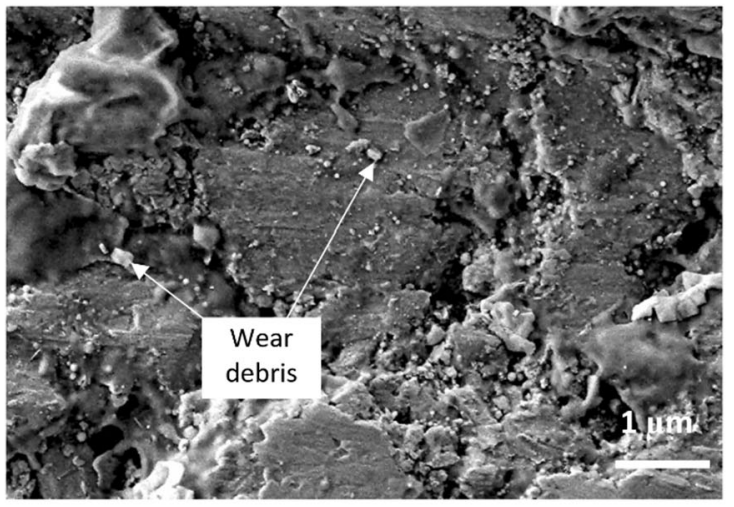

(d)

Fig. 7-SEM micrographs of wear tracks: after ball-on-flat test: (a) SC sample, $(b)$ HP sample; after pin-on-flat test: $(c)$ SC sample, $(d)$ HP sample. Different wear features are indicated by arrows. 
The tribological degradation mechanism of the composite samples involved surface oxidation (normal wear) and the rupture of particles (Figure 7). The plastic flow and tribolayers were observed, which served as a lubricant to prevent further damage. ${ }^{[30]}$

The SC sample exhibits a higher wear resistance in the pin-on-flat test than its HP analog (Figure 6(d)),

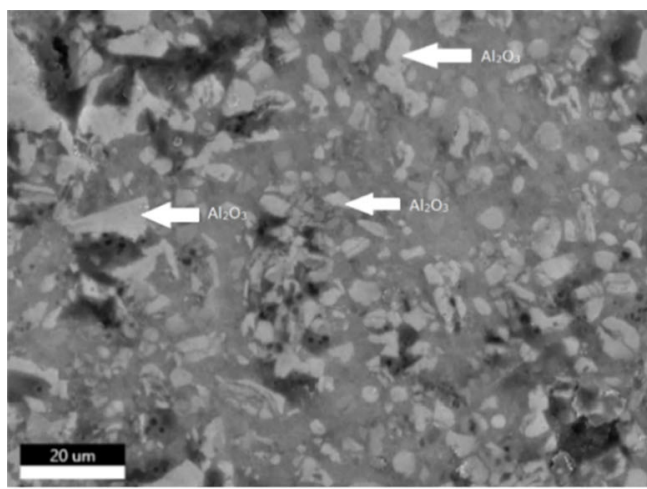

(a)

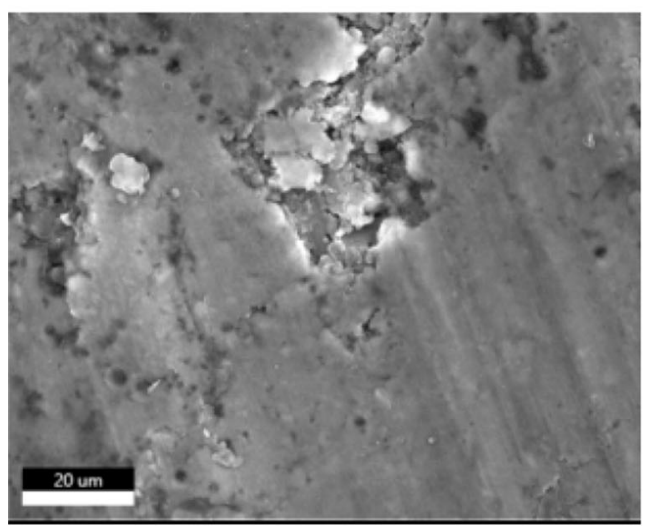

(c) whereas in the ball-on-flat test, the opposite holds true (Figure 5(d)). The much higher contact stress in the initial phase of the ball-on-flat trial (cf. Hertz model) was more detrimental to the integrity of the SC sample than for the HP sample, as reflected by the more extensive microcracking (Figure 7(a)). In the pin-on-flat test, the contact stress was lower, and the microcrack

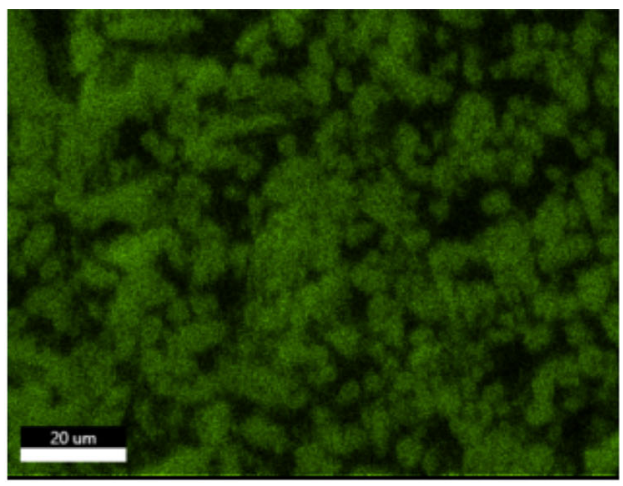

(b)

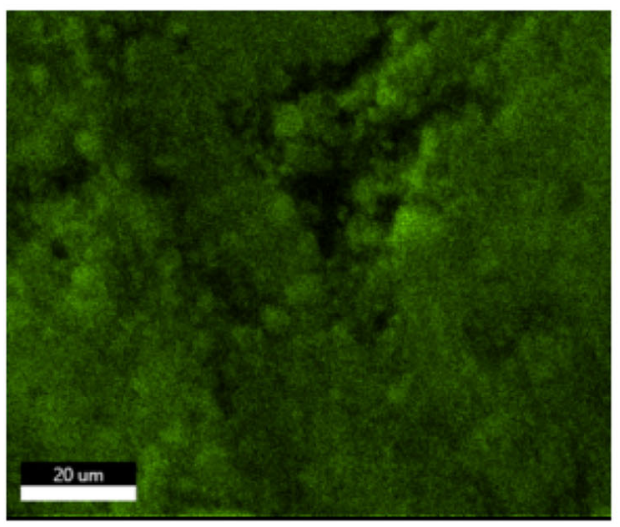

(d)

Fig. 8- Oxidation of AlSi12/ $\mathrm{Al}_{2} \mathrm{O}_{3}$ squeeze cast (SC) sample during the pin-on-flat wear test: $(a)$ SEM image of the surface before the test with aluminum oxide grains indicated by arrows; $(b)$ EDS map of oxygen distribution (line $k$ alpha) before the test; $(c)$ SEM image of the surface after the test with holes left by torn-out alumina grains; (d) EDS map showing uniform oxygen distribution (line $k$ alpha) in the worn area from figure (c).

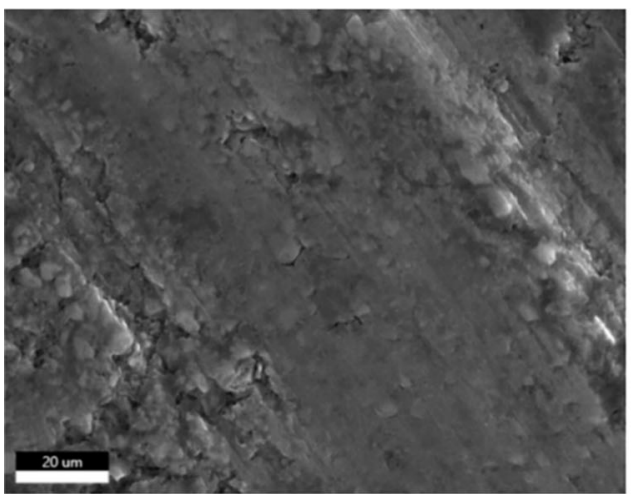

(a)

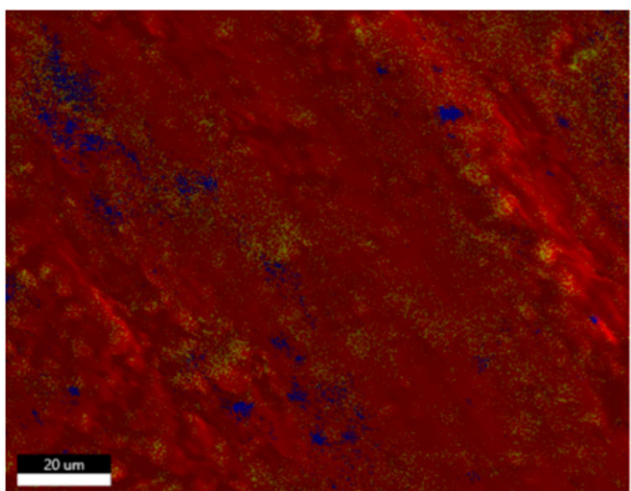

(b)

Fig. 9-Worn surface in $\mathrm{AlSi12} / \mathrm{Al}_{2} \mathrm{O}_{3}$ (HP) sample after pin-on-flat test: (a) SEM image; (b) EDS map with red color represents aluminum, yellow - oxygen, and blue - silicon; dominant presence of smeared aluminum is noticeable (Color figure online). 
damage in the SC sample was less pronounced (Figure 7(c)), whereas a large amount of wear debris was identified in the HP sample (Figure 7(d)), affecting its wear resistance (Figure 6(d)). The pin-on-flat test mimics the brake disk/pad real contact more closely. Hence, the above wear behavior seems to favor the SC composite over the HP for the desired applications.

Subsequent energy-dispersive X-ray spectroscopy (EDS) analysis demonstrated that the oxidation of the metal phase is a contributing wear mechanism. By analyzing the oxygen distribution on the sample prior to the wear test, it was determined that oxygen was only present in the alumina grains. However, after repeating the analysis post wear test, the EDS maps revealed that oxygen was uniformly distributed in the worn area (Figure 8). This mechanism was found in both the SC and HP samples tested for frictional wear.

Furthermore, EDS analysis of the worn surface in the HP sample and the debris left on the pin after the pin-on-flat test revealed smeared aluminum (Figure 9), which is an indication of tribolayer formation. ${ }^{[30]}$ Traces of aluminum were also observed on the pin surface.

Our comparative study has shown that for the investigated set of properties (Vickers hardness, flexural strength, fracture toughness, thermal conductivity, thermal residual stresses, and frictional wear), the squeeze cast composite (SC) exhibited, in most cases, superior behavior to that of the HP composite fabricated using powder metallurgy. This was most evident for the Vickers hardness measured at a load of $10 \mathrm{~kg}$, which was higher by 45 pct for the SC than HP sample, and for the flexural strength in four point bending, which was more than twice as high for the SC as compared with the HP (469 vs. $180 \mathrm{MPa})$. Advantages of the SC over the HP were also observed with regard to thermal conductivity and wear resistance in the pin-on-flat test. These differences in the SC and HP behavior were associated with the following features of the SC composite: (i) lower porosity, (ii) continuity of the alumina reinforcement, and (iii) better bonding between the alumina grains and the aluminum alloy. Consequently, the squeeze cast $\mathrm{AlSi} 12 / \mathrm{Al}_{2} \mathrm{O}_{3}$ composite seems to be a better candidate for a brake disk material than its hot-pressed analog.

\section{ACKNOWLEDGMENTS}

This research was supported by the National Science Centre (Poland) grant no. UMO-2014/15/B/ST8/04314. Fruitful discussions with Stanisław Kucharski of IPPT PAN (Warsaw) regarding the wear resistance are acknowledged.

\section{CONFLICT OF INTEREST}

On behalf of all authors, the corresponding author states that there is no conflict of interest.

\section{OPEN ACCESS}

This article is licensed under a Creative Commons Attribution 4.0 International License, which permits use, sharing, adaptation, distribution and reproduction in any medium or format, as long as you give appropriate credit to the original author(s) and the source, provide a link to the Creative Commons licence, and indicate if changes were made. The images or other third party material in this article are included in the article's Creative Commons licence, unless indicated otherwise in a credit line to the material. If material is not included in the article's Creative Commons licence and your intended use is not permitted by statutory regulation or exceeds the permitted use, you will need to obtain permission directly from the copyright holder. To view a copy of this licence, visit http://creat ivecommons.org/licenses/by/4.0/.

\section{REFERENCES}

1. D.G.C. Syu and A.K. Ghosh: Mater. Sci. Eng. A, 1994, vol. 184, pp. $27-35$.

2. S.A. Sajjadi, H.R. Ezatpour, and H. Beygi: Mater. Sci. Eng. A, 2011, vol. 528, pp. 8765-71.

3. P. Garg, A. Jamwal, D. Kumar, K.K. Sadasivuni, Ch.M. Hussain, and P. Gupta: J. Mater. Res. Technol., 2019, vol. 8, pp. 4924-39.

4. P. Gurusamy, S.B. Prabu, and R. Paskaramoorthy: Metall. Mater. Trans. A, 2015, vol. 46A, pp. 1698-1703.

5. A. Daoud, M.T. Abou El-Khair, and A.N. Abdel-Azim: J. Mater. Eng. Perform, 2004, vol. 13, pp. 135-43.

6. S.N. Chou, J.L. Huang, D.F. Lii, and H.H. Lu: J. Alloys Compd, 2006, vol. 419, pp. 98-102.

7. J. Yang and D.D.L. Chung: J. Mater. Sci, 1989, vol. 24, pp. 3605-12.

8. R. Gil, A. Jinnapat, and A.R. Kennedy: Compos. Part A, 2012, vol. 43 , pp. $880-84$

9. K.B. Lee, Y.S. Kim, and H. Kwon: Metall. Mater. Trans. A, 1998, vol. 29 , pp. 3087-95.

10. H. Chang, J. Binner, and R. Higginson: Wear, 2010, vol. 268, pp. 166-71.

11 M. Rahimian, N. Ehsani, N. Parvin, and H. Reza Baharvandi: $J$. Mater. Process. Technol, 2009, vol. 209, pp. 5387-93.

12. M.K. Surappa: Sadhana, 2003, vol. 28, pp. 319-34.

13. M. Basista, J. Maj, and W. Węglewski: Adv. Eng. Mater., 2017, vol. 19, pp. 1700484-1-1700514.

14. J. Maj, M. Basista, W. Weglewski, K. Bochenek, A. StrojnyNeedza, K. Naplocha, T. Panzner, M. Tatarková, and F. Fiori: Mater. Sci. Eng. A, 2018, vol. 715, pp. 154-62.

15. I. Sevostianov, T. Mishurova, M. Hofmann, G. Garces, and G. Bruno: Metall. Mater. Trans. A, 2020, vol. 51A, pp. 3104-13.

16. F. Scherm, R. Völkl, A. Neubrand, F. Bosbach, and U. Glatzel: Mater. Sci. Eng. A, 2010, vol. 527, pp. 1260-65.

17. A. Strojny-Nędza, P. Egizabal, K. Pietrzak, R. Zieliński, K. Kaszyca, A. Piątkowska, and M. Chmielewski: Bull. Pol. Acad. Sci. Tech. Sci., 2020, vol. 68, pp. 1227-36.

18. E. Litovsky, J.I. Kleiman, M. Shagalov, and R.B. Heimann: Surf. Coat. Technol., 2014, vol. 242, pp. 141-45.

19. ISO 23146:2012, Fine ceramics (advanced ceramics, advanced technical ceramics) -Test methods for fracture toughness of monolithic ceramics -Single-edge V-notch beam (SEVNB) method.

20. G. Meijer, F. Ellyin, and Z. Xia: Compos. B, 2000, vol. 31, pp. 29-37.

21. A. Mortensen and J.A. Cornie: Metall. Trans. A, 1987, vol. 18, pp. $1160-63$.

22. S. Roy, J. Gibmeier, V. Kostov, K.A. Weidenmann, A. Nagel, and A. Wanner: Acta Mater., 2011, vol. 59, pp. 1424-35.

23. W. Węglewski, P. Pitchai, K. Bochenek, G. Bolzon, R. Konetschnik, B. Sartory, R. Ebner, D. Kiener, and M. Basista: Met. Mater. Trans. A., 2020, vol. 51, pp. 2377-90. 
24. M. Boin and R.C. Wimpory: J. Large-scale Res. Facil., 2016, vol. 2, p. A100.

25. A.S. Wu, D.W. Brown, M. Kumar, G.F. Gallegos, and W.E. King: Met. Mater. Trans. A., 2014, vol. 45, pp. 6260-70.

26. L. Mugwagwa, D. Dimitrov, S. Matope, and I. Yadroitsev: Procedia Manuf., 2018, vol. 21, pp. 92-99.

27. S. Kucharski and Z. Mróz: Tribol. Int., 2011, vol. 44, pp. 154-64.

28. M. Eriksson, F. Bergman, and S. Jacobson: Wear, 2002, vol. 252, pp. $26-36$.
29. B.K. Prasad, A.K. Jha, S. Das, O.P. Modi, R. Dasgupta, and A.H. Yegneswaran: J. Mater. Sci. Lett., 1999, vol. 18, pp. 1731-34.

30. S.V. Prasad and R. Asthana: Tribol. Lett., 2004, vol. 17, pp. 445-53.

Publisher's Note Springer Nature remains neutral with regard to jurisdictional claims in published maps and institutional affiliations. 